\title{
Thickening of The Blekok Finger Bone (Ardeola speciosa)
}

\author{
Aghnia Nafi'Audi Tabrany*, Monica Tasya Risma Wijaya, Umi Miftakhul Jannah \\ Biology Education in Faculty of Sains and Technology, UIN Sunan Kalijaga Yogyakarta \\ Email*: nafiaudi@gmail.com
}

\begin{abstract}
Ardeola speciosa, also known as the Blekok bird, is an Aves group that has the Ardeola order. Ardeola speciosa has a size of about $46 \mathrm{~cm}$, long strands of white fur on the front and back of the head to the back. The back color is blacker. Lower body and pure is white wings. It has a gray and yellow beak with a black tip. The beak is yellow with a black tip. And has yellow feet. Each leg on Ardeola speciosa has four toes consisting of segments on each finger. On this occasion we will examine the fingers of the Blekok bird. This research was used to examine the thickening of the finger bones, before being examined the finger bones were cleaned until clean and visible bones, then cut each finger in a transverse position carefully so that the part under study was not damaged. Then it is observed in each bone whether there is thickening in the bone wall.
\end{abstract}

Keywords: Ardeola speciosa, Blekok bird, the finger bones

\section{INTRODUCTION}

Birds are one of the largest known vertebrate groups. Birds are more closely related to reptiles, which began to evolve around 135 million years ago. Around 8,600 bird species are scattered throughout the world, 3 these numbers indicate that Indonesia is the fourth richest country in the world with the number of bird species after Columbia, Peru and Brazil. Types of birds with one another bird is very similar. The most important characteristics of birds are feathers and beaks, although many other features distinguish birds from other forms of animal life. The diversity of bird species can reflect the high biodiversity of other wildlife, meaning that birds can be used as an indicator of forest quality. Various types of birds can be found in various types of habitats, including forests (primary / secondary), agroforests, plantations (palm / rubber / coffee) and open spaces (yards, rice fields, abandoned land). On this occasion we will examine birds from an open field (rice field), namely the Blekok Bird.

Blekok Bird Classification:

$\begin{array}{ll}\text { Kingdom } & \text { : Animalia } \\ \text { Phylum } & \text { : Chordata } \\ \text { Sub phylum } & \text { : Vertebrata } \\ \text { Class } & \text { : Aves } \\ \text { Order } & \text { : Ciconiiformes } \\ \text { Family } & \text { : Ardeidea } \\ \text { Species } & \text { : Ardeola speciosa }\end{array}$

This Blekok bird is a family Ardeidae that is widespread in the world, consisting of long-legged birds, long straight necks that are used to fish, small vertebrates or invertebrates. Having the characteristics of a small body size of about $45 \mathrm{~cm}$. Has a short and pointed beak. Some birds exhibit long, fine feathers that can be upheld when breeding. Nests are usually made of stacks of twigs in the tree. On this occasion we will examine the long legs of the Blekok Bird. Is there any thickening on each toe and what is the function of the thickening.

\section{METHODOLOGY}

The research method we did was first, the specimen (blekok finger bone) was prepared first. Second, the finger bone of the cleft is cleaned until it appears the layers of bone (until clean). Third, the finger bone of the blade is cut based on the segment of the finger. Fourth, each bone segment from each finger is cut using a sharp knife so that the layer of bone thickness can be observed (avoiding bone damage), and the pieces are observed one by one thickening the bones using a microscope. Fifth, the thickening of the piece that has been observed is measured using a calipers and the measurement results are obtained.

\section{RESULT AND DISCUSSION}

From the results of our study of the measurement of thickening of the blekok finger bone, namely the finger bone number $1 \mathrm{~A}$ obtained thickness of $0.04 \mathrm{~mm}$ and the finger number 1 may be thick by $0.075 \mathrm{~mm}$. At the finger bone number $2 \mathrm{~A}$ obtained thickness of $0.04 \mathrm{~mm}$, 2B $0.05 \mathrm{~mm}$, and $2 \mathrm{C}$ amounted to $0.06 \mathrm{~mm}$. On finger bone number $3 \mathrm{~A}$ obtained thickness was $0.02 \mathrm{~mm}, 3 \mathrm{~B}$ was $0.03 \mathrm{~mm}, 3 \mathrm{C}$ was $0.04 \mathrm{~mm}$, and $3 \mathrm{D}$ was $0.05 \mathrm{~mm}$. And on finger bone number 4A obtained Thickness bone of $0.03 \mathrm{~mm}, 4 \mathrm{~B}$ of $0.04 \mathrm{~mm}, 4 \mathrm{C}$ of $0.05 \mathrm{~mm}$, and $4 \mathrm{D}$ of $0.05 \mathrm{~mm}$. The data that we have obtained can be displayed in large numbers. Our assumption is that the more fingers there are, the more the functioning of the 
blekok fingers will be easier from the body of the blekok.

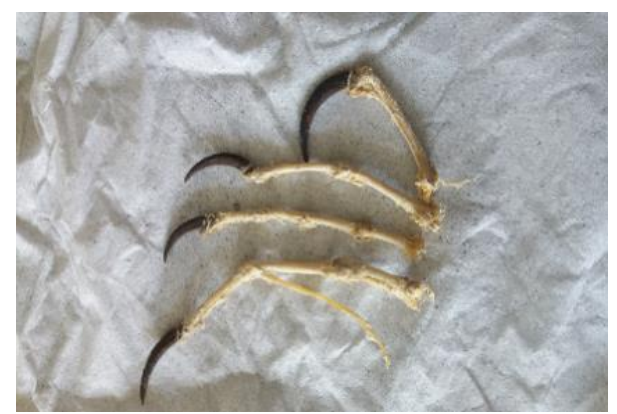

Figure 1. Four Finger Bone Blekok With An Example Of Bone Number 1 From The Top.

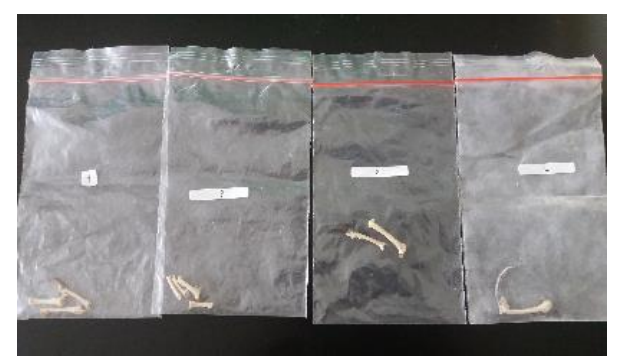

Figure 2. Blekok Finger Bones That Have Been Cut Each Segment.

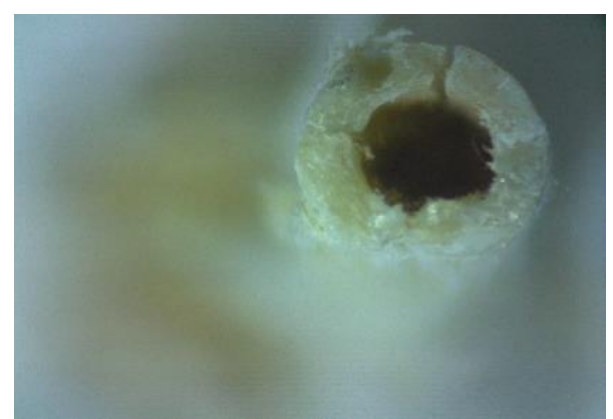

Figure 3. Blekok Finger Bone Observed With A Microscope (Number 1a) The Letter "A" Is Meant That Is A Cross Section Of The Number 1 Finger Bone Segment At The Top (Under The Nail)

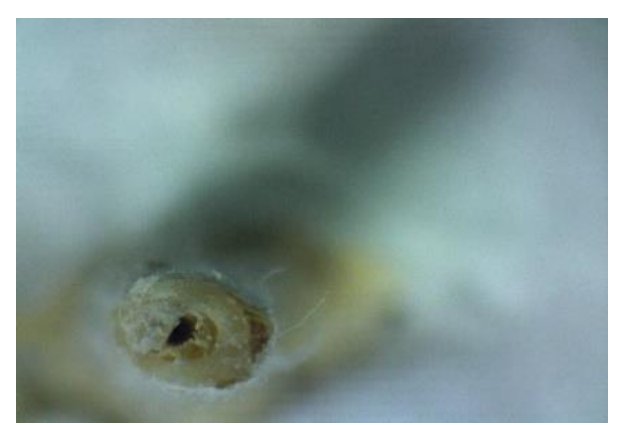

Figure 4. Blekok Finger Bone Observed With A Microscope (Number 1b), The Letter "B" In Question Is A Cross Section Of The Number 1 Finger Bone Segment At The Bottom Of 1a

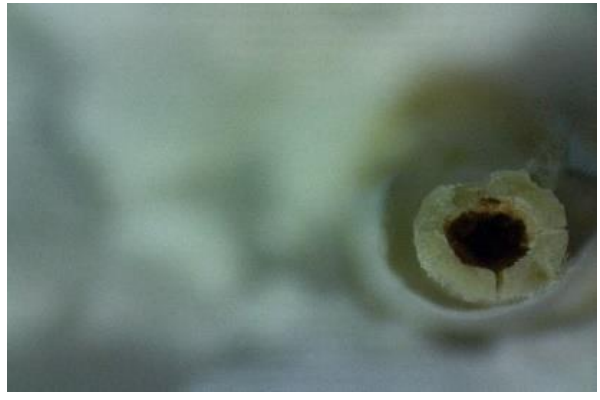

Figure 5. Blekok Finger Bone Observed With A Microscope (Number 2a) The Letter "A" Is Meant That Is A Cross Section Of The Number 2 Finger Bone Segment At The Top (Under The Nail).

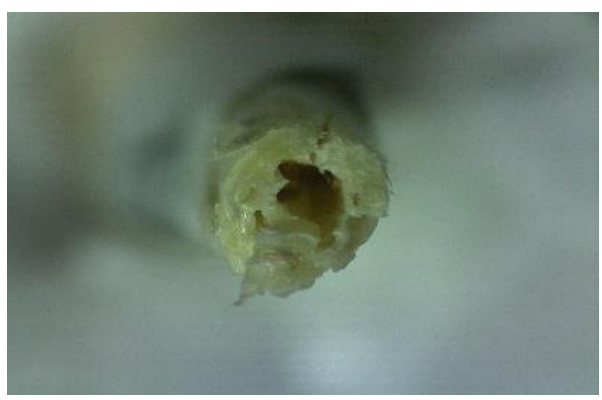

Figure 6. Blekok Finger Bone Observed With A Microscope (Number 2b), The Letter "B" In Question Is A Cross Section Of Finger Bone Segment Number 2 At The Bottom Of 2a

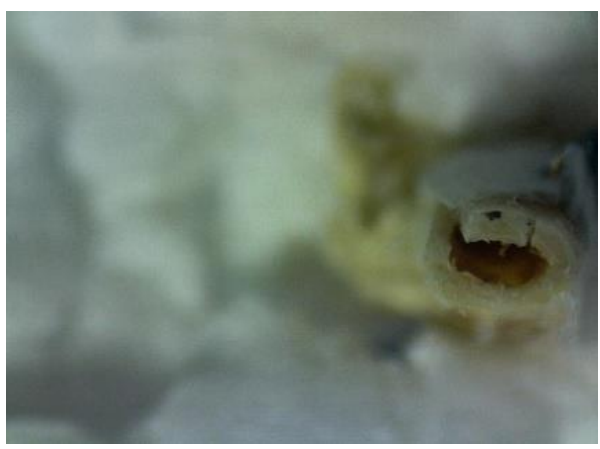

Figure 7. Blekok Finger Bone Observed With A Microscope (Number 2c), The Letter "C" In Question Is A Cross Section Of Finger Bone Segment Number 2 At The Bottom Of $2 b$

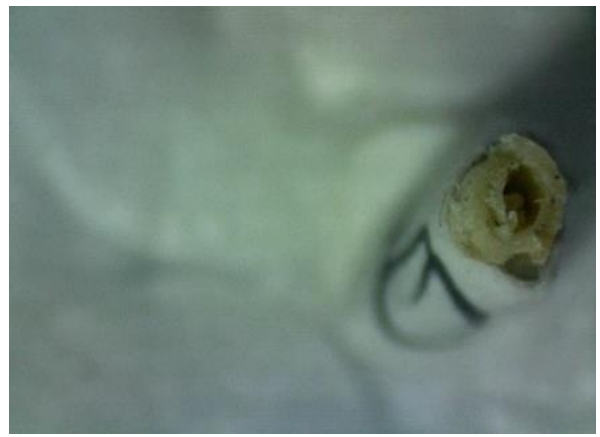

Figure 8. Blekok Finger Bone Observed With A Microscope (Number 3a) The Letter "A" Is Meant That Is A Cross Section Of The Number 3 Finger Bone Segment At The Top (Under The Nail) 


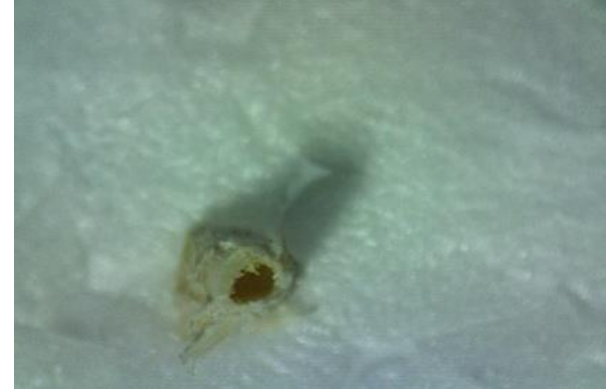

Figure 9. Blekok Finger Bone Observed With A Microscope (Number 3b), The Letter "B" In Question Is A Cross Section Of The Number 3 Finger Bone Segment At The Bottom Of 3a

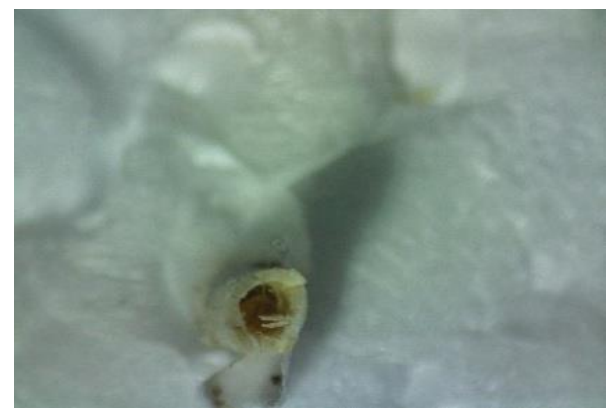

Figure 10. Blekok Finger Bone Observed With A Microscope (Number 3c), The Letter "C" In Question Is A Cross Section Of The Number 3 Finger Bone Segment At The Bottom Of 3b

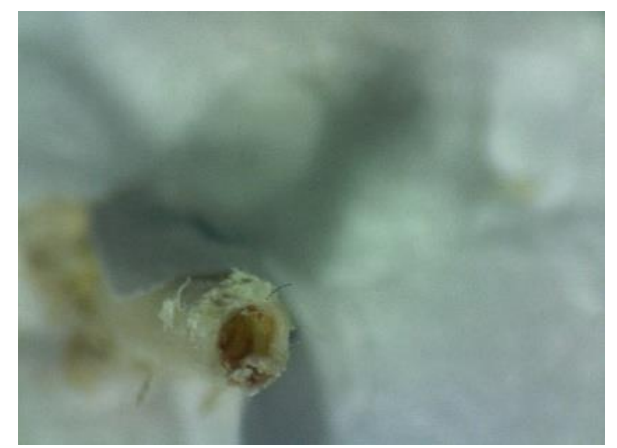

Figure 11. Blekok Finger Bone Observed With A Microscope (3d Number), The Letter "D" In Question Is A Cross Section Of Finger Bone Segment Number 3 At The Bottom Of $3 c$

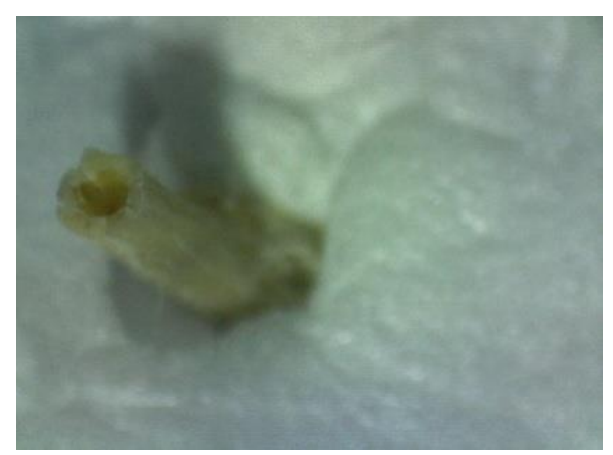

Figure 12. Blekok Finger Bone Observed With A Microscope (Number 4a) The Letter "A" Is Meant That Is A Cross Section Of The Finger Bone Segment Number 4 At The Top (Under The Nail)

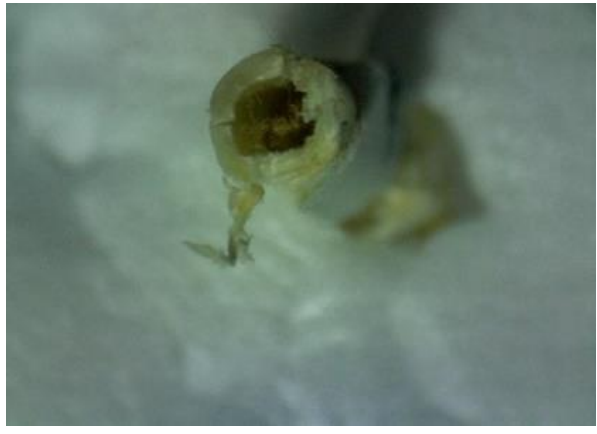

Figure 13. Blekok Finger Bone Observed With A Microscope (Number 4b), The Letter "B" In Question Is A Cross Section Of Finger Bone Segment Number 4 At The Bottom Of $4 \mathrm{a}$.

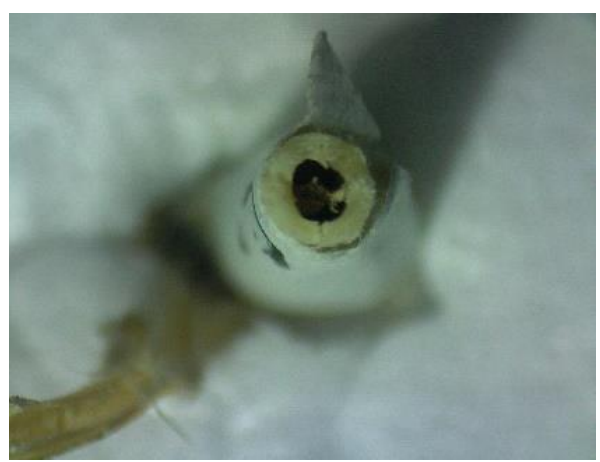

Figure 14. Blekok Finger Bone Observed With A Microscope (Number 4c), The Letter "C" In Question Is A Cross Section Of The Number 3 Finger Bone Segment At The Bottom Of $4 \mathrm{~b}$

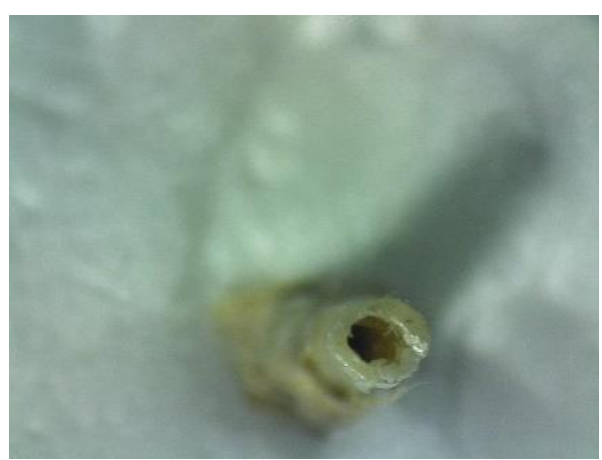

Figure 15. Blekok Finger Bone Observed With A Microscope (Number 4d), The Letter "D" In Question Is A Cross Section Of The Number 3 Finger Bone Segment At The Bottom Of 4c

\section{CONCLUSION}

Based on our research, that there is thickening of each of the blekok's finger bone segments. And it can be seen that between one finger bone with another of course different thickness, between one finger segment with another finger segment is also different. That is due to the more emphasis on the body of the blekok on the finger bone segment, because the lower the finger bone segment the thickening of the blekok is getting bigger. 


\section{REFERENCES}

Ayat, Asep. 2011. Burung-Burung Agrofrest di Sumatra. Bogor: World Agroforestry CentreICRAF.

MacKinnon, John. 1992. Panduan Lapangan Pengenalan BurungBurung di Jawa dan Bali. Yogyakarta: Gadjah Mada University Press.
MacKinnon, John. 2010. Karen Philipps dan Bas van Balen, Burung-Burung di Sumatra, Jawa, Bali dan Kalimantan. Bogor: LIPI.

Sukiya. 2001. Biologi Vertebrata. Yogyakarta: FMIPA UNY. 